\title{
ANALISIS FUNGSI KEUNTUNGAN PADA USAHATANI KEDELAI DI LAHAN SAWAH DAN DARAT
}

\author{
ANALYSIS OF PROFIT FUNCTION IN SOYBEAN FARMING \\ IN RICE FIELD AND DRY LAND
}

\author{
Rian Kurnia*, Ivan Sayid Nurahman, Saepul Aziz \\ Fakultas Pertanian, Universitas Galuh Ciamis \\ *Email:rian.agribusiness@gmal.com \\ (Diterima 19-07-2020; Disetujui 27-07-2020)
}

\begin{abstract}
ABSTRAK
Penelitian ini bertujuan untuk menganalisis pengaruh penggunaan faktor-faktor produksi terhadap keuntungan pada usahatani kedelai di sawah dan lahan kering di Kecamatan Jatiwaras Kabupaten Tasikmalaya. Sampel ditentukan dengan menggunakan Multistage Cluster Random Sampling, sehingga diperoleh ukuran sampel 127 orang dari populasi 185 orang yang terdiri atas 52 petani di sawah dan 75 petani di lahan kering. Hasil penelitian menunjukan secara simultan harga benih, harga pupuk, harga pestisida, upah tenaga kerja, luas lahan dan penyusutan alat berpengaruh sangat nyata terhadap keuntungan. Pada model II dapat diketahui bahwa penduga fungsi keuntungan mempunyai R2 sebesar 0,4960. Pada model II terlihat bahwa harga benih, harga pupuk, dan luas lahan, mempunyai hubungan negatif terhadap keuntungan; sedangkan harga pestisida, upah tenaga kerja, luas lahan, dan penyusutan alat mempunyai hubungan positif terhadap keuntungan. Secara parsial luas lahan berpengaruh nyata terhadap keuntungan.
\end{abstract}

Kata kunci: fungsi keuntungan, kedelai, lahan sawah, lahan darat

\section{ABSTRACT}

This study aims to analyze the effect of the use of production factors on profits in soybean farming in paddy fields and dry land in Jatiwaras District, Tasikmalaya Regency. The sample was determined using Multistage Cluster Random Sampling, so that a sample size of 127 people from a population of 185 people consisted of 52 farmers in the paddy fields and 75 farmers in the dry land. The results showed simultaneously the price of seeds, the price of fertilizer, the price of pesticides, labor costs, land area and the depreciation of the equipment have a very significant effect on profits. In model II it can be seen that the estimator of the profit function has an R2 of 0.4960. In model II it appears that the price of seeds, the price of fertilizer, and land area, has a negative relationship with profits; while the price of pesticides, labor costs, land area, and equipment depreciation have a positive relationship with profits. Partially the area of land has a significant effect on profits.

Keywords: profit function, soybean, rice field, dry land

\section{PENDAHULUAN}

Rata-rata kebutuhan kedelai per tahun adalah 2,2 juta ton. Pemenuhan kebutuhan kedelai sebanyak 67,99 persen harus diimpor dari luar negeri. Hal tersebut menunjukkan bahwa impor masih menjadi cara untuk memenuhi kebutuhan kedelai dalam negeri. Peningkatan produksi kedelai baik dari kuantitas maupun kualitas terus diupayakan oleh pemerintah, baik ekstensifikasi maupun intensifikasi. 
Pengembangan komoditas kedelai untuk menjadi komoditas unggulan sub sektor tanaman pangan perlu mendapat dukungan dari semua pihak yang terkait (Pusat Data dan Sistem Informasi Pertanian Kementerian Pertanian, 2017).

Menurut Pusat Data dan Sistem Informasi Pertanian Kementerian Pertanian (2017), masalah lain yang harus diperhatikan adalah produktivitas kedelai di tingkat petani yang masih rendah, rata-rata 1,3 ton per hektar dengan kisaran produksi di tingkat petani antara 0,6-2,0 ton/ha, sedangkan secara teknis potensi hasilnya dapat mencapai 3,0 ton per hektar. Belum tercapainya produktivitas tersebut sebagai akibat panggunaan sarana produksi yang belum sesuai dengan anjuran.

Kondisi tersebut menyebabkan keengganan bagi petani untuk mengembangkan tanaman kedelai, terlebih apabila harga kedelai lebih rendah dari harga jagung dan kacang hijau (Harsono, 2011; Tahir et al, 2011). Dengan demikian, perlu ada jaminan harga agar petani bergairah mengembangkan kedelai (Handayani, 2013).

Harga imput yang semakin tinggi akan mengakibatkan meningkatnya biaya produksi, dan berakibat pada keuntungan yang diterima petani semakin berkurang. Jaminan harga produk atau peningkatan harga produk, dapat meningkatkan produksi sehingga mendorong terjadinya peningkatan keuntungan. Demikian halnya apabila harga input produksi turun. Hal sebaliknya terjadi apabila harga produk turun dan harga input naik, karena banyak sedikitnya input produk yang digunakan petani akan mempengaruhi keuntungan yang diterima (Kurniati, 2015). Kondisi tersebut pada akhirnya menimbulkan berbagai persoalan dalam pengembangan kedelai, seperti bagaimana pengaruh penggunaan dan harga input produksi di tingkat petani.

\section{METODE PENELITIAN}

Data yang diperlukan pada penelitian ini adalah data primer dan data sekunder. Data primer yang diperoleh dari hasil wawancara dengan petani yang ditetapkan sebagai responden dengan menggunakan instrumen penelitian berupa kuesioner dan hasil pengamatan langsung di lapangan.

Data sekunder diperoleh dari berbagai instansi seperti: Dinas Pertanian, BPS, kecamatan, desa, laporan hasil penelitian terdahulu dan lain-lain. Selain 
petani responden, juga diwawancarai Penyuluh Pertanian Lapangan.

Metode yang digunakan dalam penelitian ini adalah metode survey pada petani kedelai di Kecamatan Jatiwaras, Kabupaten Tasikmalaya, Provinsi Jawa Barat.

Teknik pengambilan sampel dilakukan dengan cara Two Stage Cluster Random Sampling, dengan ukuran sampel 65 orang dengan proporsi 27 petani di lahan sawah dan 38 orang petani di lahan darat, dari populasi petani kedelai sebanyak 185 orang.

Sebagai perbandingan, untuk menduga koefisien fungsi keuntungan dan fungsi factor share digunakan Metode Ordinary Least Squares (OLS) dan modifikasi metode kuadrat terkecil yang dikembangkan oleh Zellner (1962) yaitu Seemingly Unrelated Regression (SUR) berdasarkan pendugaan dua tahap.

Petani kedelai dikelompokkan ke dalam dua kategori, yaitu petani kedelai lahan sawah dan darat. Masing-masing kelompok diduga secara simultan untuk fungsi keuntungan Unit Output Price (UOP) dan fungsi input tidak tetap (factor share) yang dilakukan dengan menggunakan dua model, yaitu Model I adalah pendugaan dengan menggunakan Ordinary Least Square (OLS), Model II adalah pendugaan dengan Metoda Zellner (SUR), tanpa restriksi kesamaan $\alpha_{i}{ }^{*}=$ $\alpha_{i}^{* \prime}(\mathrm{I}=1,2, \ldots \mathrm{n})$.

Dari hasil pendugaan tersebut kemudian diuji faktor-faktor apa saja yang mempengaruhi keuntungan, diuji apakah alokasi penggunaan faktor produksi telah memberikan keuntungan yang maksimum, diuji skala ekonomi usaha, dan diuji perbedaan efisiensi ekonomi relatif berdasarkan usahatani kedelai di lahan sawah dan darat.

Model persamaan penduga yang digunakan dalam penelitian ini adalah fungsi keuntungan UOP aktual dengan memasukkan tujuh peubah tidak tetap, dua peubah tetap dan satu peubah dummy. Model persamaannya adalah sebagai berikut:

$$
\begin{aligned}
i n \pi_{\alpha}^{*}=\ln & A^{*}+\alpha_{1}^{*} \ln W_{1}^{*}+\alpha_{2}^{*} \ln W_{2}^{*} \\
& +\alpha_{3}^{*} \ln W_{3}^{*}+\alpha_{4}^{*} \ln W_{4}^{*} \\
& +\beta_{1}^{*} \ln Z_{1}+\beta_{2}^{*} \ln Z_{2} \\
& +\lambda D+e_{0}
\end{aligned}
$$

Keterangan:

$\pi^{*} \quad$ : Keuntungan UOP atau keuntungan yang dinormalkan dengan harga output $(\mathrm{Rp} / \mathrm{kg})$

$\ln A^{*} \quad$ : Konstanta

$W_{1}^{*} \quad$ : Harga benih yang dinormalkan dengan harga output $(\mathrm{Rp} / \mathrm{kg})$

$W_{2}^{*} \quad$ : Harga pupuk yang dinormalkan dengan harga output $(\mathrm{Rp} / \mathrm{kg})$ 
$W_{3}^{*} \quad: \quad$ Biaya pestisida yang dinormalkan dengan harga output (Rp/musim tanam)

$W_{4}^{*} \quad$ : Upah tenaga kerja yang dinormalkan dengan harga output $(\mathrm{Rp} / \mathrm{HOK})$

$Z_{1} \quad$ : Luas lahan (hektar/musim tanam)

$Z_{2} \quad$ : Biaya peralatan (Rp/musim tanam)

$\alpha_{i}^{*} \quad$ : Parameter input variabel yang diduga, $i=1,2,3$, dan 4

$\beta_{j}^{*} \quad$ : Parameter input tetap yang diduga, $\mathrm{j}=1,2$

\section{HASIL DAN PEMBAHASAN}

Pendugaan Fungsi Keuntungan Usahatani Kedelai

Seperti yang telah dijelaskan pada uraian sebelumnya, bahwa pendugaan parameter digunakan persamaan fungsi keuntungan UOP (Unit Output Price) dan persamaan fungsi factor share. Pendugaan tersebut dilakukan berdasarkan metode SUR (Seemingly Unrelated Regression) yang ditemukan oleh Zellner (1962). Pengolahan data dalam penelitian ini menggunakan alat bantu komputer dengan program STATA.

Input variabel yang digunakan sebagai variabel bebas meliputi harga benih yang dinormalkan $\left(\mathrm{W}_{1}{ }^{*}\right)$, harga pupuk yang dinormalkan $\left(\mathrm{W}_{2}{ }^{*}\right)$, harga pestisida yang dinormalkan $\left(\mathrm{W}_{3}{ }^{*}\right)$, upah tenaga kerja yang dinormalkan $\left(\mathrm{W}_{4}{ }^{*}\right)$, luas lahan yang dinormalkan $\left(\mathrm{Z}_{1}^{*}\right)$ dan penyusutan alat yang dinormalkan $\left(\mathrm{Z}_{2}{ }^{*}\right)$ dan. Adapun lima variabel yang dimaksud diatas adalah harga benih $\left(\mathrm{X}_{1}\right)$, harga pupuk $\left(\mathrm{X}_{2}\right)$, harga pestisida $\left(\mathrm{X}_{3}\right)$, upah tenaga kerja $\left(\mathrm{X}_{4}\right)$, luas lahan $\left(\mathrm{X}_{5}\right)$ dan penyusutan alat $\left(\mathrm{X}_{6}\right)$.

Pendugaan parameter fungsi keuntungan UOP (Unit Output Price) dalam penelitian ini disajikan dalam 2 model, yaitu model I menggunakan persamaan tunggal metode $O L S$ (Ordinary Least Square), Model II menggunakan persamaan silmultan SUR (Seemingly Unrelated Regression) Zellner tanpa kesamaan $\alpha^{*}=\alpha^{*}$ yang berarti terjadinya keuntungan aktual jangka pendek. Analisis pendugaan fungsi keuntungan ini menggunakan Unit Output Price Cobb Douglas Profit Function, merupakan suatu fungsi atau persamaan yang melibatkan harga faktor produksi dan nilai produksi yang telah dinormalkan dengan harga kedelai lahan darat maupun lahan sawah. Cara ini juga mendasarkan pada asumsi bahwa petani atau pengusaha adalah memaksimumkan keuntungan. Hasil pendugaan fungsi 
keuntungan UOP (Unit Output Price) dapat dilihat pada Tabel 1.

Tabel 1. Pendugaan Fungsi Keuntungan Usahatani Kedelai di Kecamatan Jatiwaras Kabupaten Tasikmalaya

\begin{tabular}{|c|c|c|c|}
\hline \multirow{2}{*}{ Variabel } & \multirow{2}{*}{ Parameter } & \multicolumn{2}{|c|}{$\begin{array}{c}\text { Koefisien Regresi } \\
\text { Model }\end{array}$} \\
\hline & & $\mathbf{I}$ & II \\
\hline Konstanta & $A^{*}$ & $\begin{array}{c}0.117 \\
(0.978)\end{array}$ & $\begin{array}{c}0.117 \\
(0.977)\end{array}$ \\
\hline $\ln W_{1}^{*}$ & $\alpha{ }_{\alpha 1}^{*}$ & $\begin{array}{l}-0.537 \\
(0.725)\end{array}$ & $\begin{array}{l}-0.537 \\
(0.717)\end{array}$ \\
\hline $\operatorname{lnW}_{2}{ }^{*}$ & $\alpha 2^{*}$ & $\begin{array}{l}-1.135 \\
(0.238)\end{array}$ & $\begin{array}{l}-1.135 \\
(0.223)\end{array}$ \\
\hline $\operatorname{lnW}_{3}{ }^{*}$ & $\alpha{ }^{*}$ & $\begin{array}{c}1.110 \\
(0.450)\end{array}$ & $\begin{array}{l}1.110 \\
(0.436)\end{array}$ \\
\hline $\ln W_{4}{ }^{*}$ & $\alpha 4^{*}$ & $\begin{array}{c}0.713 \\
(0.826)\end{array}$ & $\begin{array}{c}0.713 \\
(0.821)\end{array}$ \\
\hline $\ln Z_{1}$ & $\beta 1^{*}$ & $\begin{array}{l}-0.016 \\
(0.000)\end{array}$ & $\begin{array}{l}-0.016 \\
(0.000)\end{array}$ \\
\hline $\ln Z_{2}$ & $\beta 2^{*}$ & $\begin{array}{c}0.604 \\
(0.000)\end{array}$ & $\begin{array}{c}0.604 \\
(0.000)\end{array}$ \\
\hline $\begin{array}{r}\text { R-sq } \\
\text { Pr }\end{array}$ & $\begin{array}{l}\text { ared } \\
\text { b. }\end{array}$ & $\begin{array}{c}49,60 \% \\
0.000\end{array}$ & $\begin{array}{c}49,60 \% \\
0.000\end{array}$ \\
\hline
\end{tabular}

Keterangan:

Model I : Pendugaan dengan metode OLS

Model II: Pendugaan dengan metode Zellner tanpa restriksi

Angka dalam ( ) adalah probability value

Nyata pada derajat kepercayaan $95 \%(\alpha=0,05)$

***signifikan pada 0,01 atau $1 \%$

Berdasarkan hasil diatas diperoleh persamaan fungsi keuntungan metode Zellner adalah sebagai berikut:

Persamaan:

$$
\begin{gathered}
\ln \mathrm{Y}=\ln \beta 0+\beta 1 \ln \mathrm{X} 1+\beta 2 \ln \mathrm{X} 1+\beta 3 \\
\ln \mathrm{X} 3+\beta 4 \mathrm{X} 4+\beta 5 \mathrm{Z} 1+\beta 6 \mathrm{Z} 2
\end{gathered}
$$

sehingga:

$$
\begin{gathered}
\ln \mathrm{Y}=0.117+(-0.537) \mathrm{X} 1+(-1.135) \mathrm{X} 2 \\
+1.110 \mathrm{X} 3+0.713 \mathrm{X} 4+(-0.016) \mathrm{Z} 1+ \\
0.604 \mathrm{Z} 2
\end{gathered}
$$

Uji F yaitu uji untuk melihat bagaimanakah pengaruh seluruh variabel bebas secara bersama-sama terhadap variabel terikat dan untuk menguji apakah model regresi yang kita buat signifikan atau tidak signifikan. Melalui uji F, hubungan secara simultan dapat diketahui bahwa hubungan antara keuntungan usahatani kedelai sebagai variabel terikat dengan 6 (enam) variabel bebas yang terdiri atas harga benih, harga pupuk, harga pestisida, upah tenaga kerja, luas lahan dan penyusutan alat menunjukkan hubungan sangat nyata dengan p-value $=0,000$. Pada model II dapat diketahui bahwa penduga fungsi keuntungan mempunyai $R^{2}$ sebesar 0,4960, hal ini berarti bahwa variabel bebas dapat menjelaskan variasi dalam variabel terikat (variabel keuntungan) mempunyai pengaruh yang sedang sebesar 49,60\%, sedangkan sisanya $50,40 \%$ dipengaruhi faktor lain di luar model yang dianalisis. Jika nilai $R$ Square mendekati satu maka keterikatan variabel bebas dalam menjelaskan variabel terikat semakin tinggi, sementara jika dijumpai $R^{2}$ bernilai minus (-), maka dapat dikatakan bahwa tidak terdapat pengaruh variabel bebas dan variabel terikat. Semakin kecil nilai koefisien determinasi 
$\left(R^{2}\right)$, maka keterikatan variabel bebas dan variabel terikat semakin lemah.

Apabila dilihat dari pengaruh masing-masing variabel bebas terhadap keuntungan usaha, pada tabel Model II tampak bahwa harga benih, harga pupuk, dan luas lahan, mempunyai hubungan negatif terhadap keuntungan usaha, sedangkan pada harga pestisida, upah tenaga kerja, luas lahan, dan penyusutan alat mempunyai hubungan positif terhadap keuntungan usaha.

Dari keenam input yang nyata mempengaruhi keuntungan usahatani adalah luas lahan dengan koefisien regresi sebesar -0,016 (prob. sebesar 0,000), artinya semakin bertambahnya luas lahan, maka keuntungan yang diterima semakin kecil, dan penyusutan alat dengan koefisien regresi sebesar 0,604 dan (prob. 0,000) dengan derajat kepercayaan $95 \%$, artinya semakin tinggi nilai penyusutan, maka keuntungan semakin tinggi, hal ini dikarenakan peralatan yang digunakan merupakan peralatan yang dapat bertahan lama atau harga yang timbul sebagai akibat berlalunya waktu sehingga akan mengurangi harga tetap permusimnya. Sedangkan yang tidak berpengaruh nyata terhadap keuntungan usahatani adalah harga benih (prob. 0,717), harga pupuk (prob. 0,223), harga pestisida (prob. 0,436), upah tenaga kerja (prob. 0,821), dan dengan tingkat kepercayaan 95\%.

Hal ini dikarenakan benih kedelai, merupakan input variabel yang penggunaan benih yang tidak selektif sehingga menyebabkan mutu bibit yang kurang baik sedangkan penggunaan pupuk dan pestisida, kurang efektif dalam penggunaannya, dan upah tenaga kerja yang tidak sesuai sehingga menyebabkan kualitas output yang tidak optimal hal ini merupakan pemborosan yang menyebabkan meningkatnya harga produksi.

\section{KESIMPULAN DAN SARAN}

\section{Kesimpulan}

Analisis fungsi keuntungan menunjukan luas lahan dan penyusutan alat berpengaruh secara signifikan sedangkan harga benih, harga pupuk, harga pestisida serta upah tenaga kerja tidak berpengaruh nyata.

\section{Saran}

Melihat tingkat keuntungan yang tercapai produsen tidak saja ditentukan oleh besar kecilnya produksi melainkan juga oleh harga-harga input dan output maka ketika musim tanam padi telah tiba maka pemerintah berperan dalam 
pengendalian kelancaran distribusi sarana

produksi khususnya ketersediannya

pupuk dan kestabilan harga input lainnya

\section{DAFTAR PUSTAKA}

Badan Pusat Statistik. 2017. Statistik Indonesia 2017. Katalog: 1101001. https://www.bps.go.id/website/pdf publikasi/Statistik-Indonesia2017.pdf. Diakses pada Agustus 2018 .

Badan Penelitian dan Pengembangan Pertanian. 2018. www.litbang.pertanian.go.id. Diakses pada Agustus 2018.

Gujarati, Damodar N. 2006. Dasar-Dasar Ekonometrika. Edisi Ketiga. Penerbit Erlangga. Jakarta.

Lau, L. J., and P. A. Yotopaulus. 1971. A Test for Realative Efficiency and
Application to Indian Agriculture. American Economic Review.

Yotopoulos, Pan, A and Nugent, Jeffrey B. 1976. Economics of Development (Empirical Investigations) Harper International Edition. Harper \& Row Publishers. New York.

Zellner, A., 1962, An Efficient Method of Estimating Seemingly Unrelated Regressionand Tests for Aggregation Bias. Journal of the American Statisticial Association, 57(298): 348-368.

Kurniati, D. 2015. Perilaku petani terhadap risiko usahatani kedelai di Kecamatan Jawai Selatan Kabupaten Sambas. Jurnal Social Economic of Agriculture. Universitas Tanjungpura. Pontianak, 4(1): 32-36. 